\title{
INTRODUCCIÓN A LA REALIDAD SOCIO-HISTÓRICA INMERSA EN EL TÉRMINO "PLAZA" Y SU EXPRESIÓN MATERIAL EN LA ARQUEOLOGÍA
}

\author{
Introduction to socio- historical reality immersed \\ in the term "square" and its material expression in archeology
}

Manuel Castillo Poveda*

\section{RESUMEN}

En el presente trabajo se indagara el origen, desarrollo, su componente histórico-cultural con que fue constituido dicho vocablo, así como la evidencia material que refleja el concepto de plaza en el campo de la arqueología; tal ejercicio permitirá el construir una noción actualizada y fundamentada del significado del término plaza, además de vislumbrar la política que el mismo promueve.

Palabras clave: arqueología, plaza, deconstrucción, historia, materialidad, sociedad, política.

\begin{abstract}
In this paper we inquire into the origin, development, historical and cultural component that was made that term, as well as evidence material that reflects the concept of place in the field of archeology; such exercise will allow to build an updated and informed of the meaning of notion square, plus a glimpse of politics that it promotes.

Key Words: archeology, square, deconstruction, history, materiality, society, politics.
\end{abstract}

Universidad de Costa Rica. Antropólogo y Arqueólogo. Costa Rica.

Correo electrónico: povedaarq@gmail.com

Recepción: 3/11/15. Aceptación: 3/8/16. 


\section{Introducción}

La historia que nos antecede influye en la constitución de nuestra identidad como personas, el lenguaje de igual manera posee rastros sobre políticas, ideologías o significados con el cual fue concebido; es por ello que su utilización debe realizarse con cautela, ya que se podría expresar ideas contrarias a una postura propuesta por el descuido de no llevar a cabo una revisión de los conceptos tratados.

Tal argumento aboga por un uso íntimo del lenguaje, donde podemos apreciar su bagaje histórico, conocer su propuesta existencial atinente a un tópico especifico y no como utilería vacua, ausente de un transitar, así de una relación con el ser humano.

Cabe recalcar la importancia de dicha práctica de ahondamiento en el significado de un concepto dentro de las ciencias sociales, campos de estudio que trabajan con identidades, tradiciones, poblaciones ajenas a la constitución social occidental-moderna, como a marcos temporales; por lo cual, el referir, adjudicar o utilizar términos asociados a los mismos implica una conjugación de los valore de lo referido como de lo referente.

Además, se adjudica la obligatoriedad de que todo concepto emitido en dicho campo de investigación se sustente mediante evidencia, esto debido a la correspondencia de estas disciplinas no solamente con lo estudiado, si no con la institución de la ciencia, la cual exige la comprobación de lo investigado mediante su fundamentación.

Ante tal panorama surge la interrogante de ¿Cómo ahondar en esta gama de connotaciones históricas que influencian los conceptos a utilizar?, cabe resaltar que no se pretende el llegar a un significado prístino de un término, pero si conocer su trazo por la historia, de tal manera generar un entendimiento del mismo; esto mediante su deconstrucción.

El filósofo Francés Jaques Derrida, en su texto "Of Grammatology" (1967) propone la deconstrucción como un proceso de análisis; donde se pretende obtener una noción próxima del significado de determinada idea expresada.
De dicha manera se podría ahondar en las distintas relaciones, influencias y significados de los que puede gozar un concepto.

Tomando este proceso como base, se llevara a cabo un recorrido por el ámbito etimológico, histórico, científico y material que envuelve el concepto de plaza en la historia costarricense, de esta amanera se conocerá acerca del mismo y discutirá de su utilización como se correspondencia fáctica en el campo de la arqueología.

\subsection{Del concepto a la realidad}

Con el fin de esclarecer lo referido en un trabajo o cualquier interacción humana verbal o escrita, es necesaria la continua revisión de los conceptos utilizados al momento de expresar una idea; ya que es por medio de estos que se promueven determinadas políticas, cargas histórico o cognitiva; mismas que puede evocar confusión, equivocación o malversación en un discurso.

Es por esta razón que se hace necesario indagar sobre los términos ejes a desarrollar en un trabajo, esta acción evoca una concientización en la construcción de la investigación e investigador, retrotrayendo los matices con que fue impregnado determinado término, así como evocando su reflexión y ligamen con la realidad vivida.

Para tal labor es necesario un volver temporal y espacial, con el propósito de ser conscientes de las distintas perspectivas que se le ha asignado al concepto tratado. Es de sumo beneficio para dicha indagación, quede registradas en escritura, ya que es un eficaz medio de difusión; sin embargo hay ámbitos en que no se goza de tal propiedad; este es el caso de la arqueología en donde la lectura y comprensión de los datos evoca la búsqueda de un método distinto.

En ciertos casos, las poblaciones antiguas no dejaron evidencia escrita o gráfica, que en cuyo caso, hasta el momento no se ha podido cifrar, sin embargo, la materialidad que se halla de las mismas, como lo es la cerámica, arquitectura, lítica, el espacio y el tiempo, nos 
permiten abordar temas atinentes al vivir de dichas sociedades.

Entre estos factores que fundamenta el indagar y dar a entender la realidad vivida por estas sociedades, recae en la subjetividad del investigador, ya que depende de su experiencia con el contexto trabajo, la lectura de la evidencia según su método de estudio, así como, el marco explicativo escogido, con el fin de situar sus resultados en un mundo de raciocinio (teoría).

Es por ello que el arqueólogo tiene la responsabilidad de ser consiente del trasfondo de los conceptos utilizados en su labor, así como de su difusión. Cabe recalcar que dicho investigador debe de llevar a cabo una traducción de lo investigado a términos que forman parte del contexto socio-histórico del cual se formó, con el fin de constituir la evidencia a un lenguaje entendible para él y a la población que responde.

Ateniente al concepto de plaza, en el ámbito arqueológico costarricense dicho término se ha utilizado desde los primeros reportes de arquitectura precolombina (Hartman, 1901), sin fundamentar que significa dicha denominación. Es hasta el 2014, que se lleva a cabo el trabajo "Paisaje y arqueologia: Arquitectura y conceptualización de las manifestaciones P-01, P-02, P-03 y "encierro" 1 en el sitio arqueológico Nuevo Corinto (L-72NC), Caribe Central, Costa Rica", el cual desarrollo dicha temática a profundidad, evidenciando la realidad etimológica, sociohistórica y material de dicho termino, investigación base para el presente artículo.

\subsection{Las percepciones de plaza en la historia de la arqueología}

La noción actual del término "plaza" puede retrotraerse hasta la cultura romana (foro [forum] "lugar de una ciudad donde se

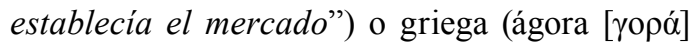
"espacio abierto, centro del comercio/mercado], de la cultura y la política de la vida social de los griegos") (Mumford, 1979: 254, 272), la cual refiere a un lugar diferenciado del tránsito común en un poblado o urbe. Es decir, un espacio público específico dentro de un razonamiento de tránsito funcional en un conjunto de edificaciones y dentro de un esquema de posicionamiento. Asimismo, se enfatiza dicho lugar como un sitio en el que se pueden llevar a cabo una variedad de actividades en las que se potencia la participación popular, a manera de un "lugar abierto o espacio público circundado por edificios" (Diccionario de arquitectura y construcción, 2013).

Aunque dicho trazo histórico del concepto remite a una "pluralidad" de manifestaciones culturales activas en este espacio, existen perspectivas donde se enfatizó una función específica, ejemplo de ello es su apreciación en la época Barroca; donde era sinónimo de centro de poder político-ideológico, así como ícono de la memoria colectiva en la Francia del siglo XVIII (Campos, 2011: 102).

Por su parte, en las Indias (en 1573) funcionó como un elemento de dominio español ante tal nación y, a la vez, como esquema de ordenamiento social (Hardoy y Aranovich, 1969) "En la Plaza Mayor de Las Palmas, se concentraron los edificios destinados a la máxima jerarquía de la ciudad (el Cabildo), la instancia judicial más elevada (la Audiencia) y la Catedral y algo muy parecido se repite en las plazas mayores de Hispanoamérica" (Humbolt, 1956: 365).

Costa Rica no logró escapar a dicho fenómeno. Por medio de la implementación en la colonia del esquema de organización espacial denominado "plano damero", el cual refiere a una cuadrícula extendida en un poblado (en cuadras de aproximadamente $100 \mathrm{~m}$ de largo), se estableció como eje central un sitio nombrado como "plaza". "Dada la importancia de las plazas como foco aglutinador de la vida de las poblaciones, las casas se levantaban en sus inmediaciones" (González, 1990: 102); dicho espacio era abierto, sin obstáculos y con la presencia de expresiones verdes (árboles, plantas, zacate, entre otros) "Arboles o plantas, es importante destacar este detalle, parece que nunca existieron con intención de ornamento, o como elementos de sombra en las plazas" (Gonzales, 1990: 104). 
De tal manera, "la racionalidad de una planificación urbana ortogonal nos emplaza en primer lugar frente al problema de la elaboración de un modelo urbanístico y, por ende, ante un planteamiento teórico del mismo" (Menéndez, 1997: 184). Se presupone que esta estructura de ordenamiento del territorio se impulsó como "natural". Desde ese momento, en el contexto nacional, se utilizó el término "plaza" sin cuestionar su significado y definición; sino que se asumió lógico. En el caso de la arqueología, dicha idea fue extrapolada a maneras de distribución socio-natural pertenecientes a las poblaciones indígenas y la evidencia precolombina.

\begin{abstract}
Su trazado hablaba de prácticas espaciales que procuraban afirmar autoridad sobre el espacio urbano, procurando una correspondencia entre discurso y morfología urbana. La cuadrícula hispanoamericana en este sentido, nos remite a los valores de la espacialidad moderna, abstracta, neutra [supuestamente] y homogénea, construida desde el Renacimiento en Europa y a una cartografía que procuraba asimismo una racionalidad espacial, constituyendo un instrumento de colonización y desterritorialización del espacio indígena (Padrón, 2002: 29).
\end{abstract}

Lo cual eclipsó la búsqueda de otras perspectivas que podrían abarcar el entendimiento de estos espacios; "la traza colonial pudo haber sido un vehículo para el trasplante del orden social, político y económico e incluso una encarnación del cuerpo mismo de la "república urbana" (Morse, 1972: 69).

Varios de estos vicios interpretativos delimitaron las formulaciones acerca de la noción de los espacios de interés (arqueológicos) a la presuposición de un único esquema de ordenamiento, como de razonamiento (mencionado con anterioridad), invisibilizando la opción de concebir edificaciones hechas de materiales perecederos cercanos a los mismos, negando significados compartidos entre elementos estructurales; así como la no pluralidad de connotaciones que reflejaría un complejo arquitectónico de este tipo.

En los casos en que el espacio denominado "plaza" se enfatiza como una sola expresión cultural general, se contraviene la idea evocada de dicho lugar (y la definición literaria de su ser [un espacio construido a partir de la dinámica de la sociedad en una pueblo o ciudad]), así como de las realidades sociales (actividades diarias) donde se instauraron estas estructuras; ello debido a la multiplicidad de usos en los cuales pudo participar, acorde con la noción establecida (militar, comercial, funeraria).

Volviendo al esquema de "plano damero", este se utilizó como una manera efectiva de ordenamiento territorial $\mathrm{y}$, dentro del mismo, se infiere que las "plazas" "desde los momentos más tempranos [sic] de cada población, se configuraron como un espacio diáfano fundamental para la organización morfológica de los tejidos construidos" (Croché de Acuña, 1981: 59-63) y como un símbolo de la presencia de la conquista. Es más, algunos han argumentado que es producto "de la estética urbanística del convento, un caso de españolidad reclusa, que tiene su origen en el claustro, y responde al sentimiento de la intimidad de la vida musulmana" (Chueca, 1981: 94). No está demás insistir que la idea de plano damero ha estado presente a lo largo de la historia oficial costarricense (Corrales et al., 1988).

Retomando lo comentado por el arqueólogo Alex Geurds, a las "plazas" las refiere como "espacios que no tienen nada" (Alex Geurds, arqueólogo, comunicación personal, 2011). Dicha nominación no necesariamente enfatiza la ausencia de un significado específico de tales lugares, sino (y cabe leer esto desde Heidegger, 1927) que esa nada explícita es una nada nadiante; la cual emite la posibilidad de poder manifestar cualquier expresión evocada por su medio y participantes.

Con dicha afirmación, es evidente que la constitución de un espacio está regida por diversos fenómenos, los cuales se conjuntan para dar sentido a un lugar. Por el contrario, si este se toma solo analíticamente el único resultado será la contabilización de un número de partes sin ningún paisaje (1) referido.

Es por ello que las "plazas" no deben ser leídas solo como lugares vacíos y sin obstáculos, 
sino como la posibilidad de conjunción de diversos elementos (estructuras a su alrededor, así como sus delimitantes, topografía, altitud, material asociado, panorámicas, ubicación y otras variables [agua, luz, fuego, entre otros]), que pueden expresar una idea que contiene el complejo arquitectónico y sí evocan un sentir social; "el Dasein no es tan sólo un ente que se presenta entre otros entes. Lo que lo caracteriza ónticamente es que a este ente le va en su ser este mismo ser" (Heidegger, 1927: 22).

Respecto a la expresión material de la idea referida al término "plaza", esta es caracterizada por ser un lugar demarcado por estructuras, pero que posee una entidad propia; y no se reduce a los elementos que le delimitan. Además, se asocia a áreas públicas, lo que confiere la idea de elección colectiva por ocupar dicho sitio y no la confinación (o contención) de personas en él.

Por lo antes dicho, es necesario hacer un repaso de los distintos trabajos arqueológicos realizados en los espacios de interés dentro del contexto nacional; esto con el fin de llevar a cabo una reflexión acerca de los mismos y proponer términos acordes con la información y evidencia arqueológica disponible, así como al contexto socio-cultural al cual pertenecemos. Todo ello con el objetivo de que haya una identificación con la idea expresada por el mismo.

Cabe destacar que lo propuesto estará sujeto a asociaciones con definiciones de espacios occidentales, esto debido a que no se tiene evidencia lingüística o escrita precolombina que pueda asignarse a un lugar en específico dentro un conjunto de estructuras antiguas. Además, es necesaria la traducción a conceptos propios del entorno desde donde se investiga, esto con el fin de construir una idea de lo abarcado de acuerdo a nuestra realidad.

Quien crea que ciertos conceptos son los correctos sin más; que quien tuviera otros, no apreciaría justamente algo que nosotros apreciamos - que se imagine que ciertos hechos naturales muy generales ocurren de manera distinta a la que estamos acostumbrados, y le serán comprensibles formaciones conceptuales distintas a las usuales (Wittgenstein, 1999:190).

\subsection{La noción de plaza y su discurso en la arqueología costarricense}

Como primer paso en la comprensión del concepto de plaza, se expondrá como premisa que dichas manifestaciones son el resultado de la apropiación del entorno, por medio de la edificación de estructuras con el fin de reflejar una idea; "por idea entiendo las imágenes débiles de estas en el pensamiento $y$ razonamiento" (Hume, 2001: 20). De esa forma "el espacio no es ni un objeto externo, ni una experiencia interna. No podemos situar al hombre [sic] y al espacio uno al lado del otro" (Heidegger, 1927: 31).

Dicha apreciación entiende la consciencia de ser con su ámbito físico "la existencia es espacial” (Bollnow, 1963: 154), evocando una intimidad entre ambos "la relación del hombre [sic] con los lugares $y$, a través de ellos, con los espacios, se constituye en la residencia" (Norberg-Schulz, 1967: 104). Por lo cual, se expresa la relación existencial entre el ser humano y el espacio en que habita, está por medio de un entramado cognitivo, "un sistema relativamente estable de esquemas perspectivos o imágenes del ambiente circundante" (Parsons 1966: 5), el cual valoriza, diferencia y trasforma el vivir.

Es por ello y necesario fundamentar el concepto utilizado para expresar u clasificar un espacio estudiado "El discurso es la articulación 'significante' de la comprensibilidad del estar en el mundo, estar en el mundo al que le pertenece el coestar, y que siempre se mantiene en una determinada forma del convivir ocupado" (Heidegger, 1927: 164); esto debido a que preconcebimos la palabra como un eje de expresión del ser humano de una realidad vivida.

La misma, al poseer distintos matices, puede ser equívoca o delimitante al tratar de dar a entender la idea que contiene; es por ello que un concepto busca cómo especializarse en su propósito de expresión: "nos dirige aquello que en todo y por debajo de todo está presentándose y permanece en su presencia: el ser o esencia en sentido activo" (Heidegger, 1927: 180). 
Respecto a la noción del espacio denominado como "plaza" en la arqueología, Los trabajos de Doris Stone (1976), Snarskis (1978), Hurtado de Mendoza y Gómez (1985), Garnier y Troyo (2002), Troyo (1998) y Hurtado de Mendoza y Troyo (2007-2008) entienden dicha expresión espacial como sino como un aditivo o engranaje de otras estructuras y no como un elemento con significación independiente.

Estos trabajos infieren los lugares en cuestión como un aditivo de un conjunto estructural que involucra de igual manera a otras edificaciones (montículos); ello evoca que las "plazas" se traten sólo con relación a otros elementos, con los cuales intima. No obstante, estas no pueden depender de otro para ser, es decir, la entidad de dicho lugar no remite solo a su relación con otra unidad arquitectónica, sino a la conjunción entre estas para la expresión de una idea. 'La 'presuposición' del ser tiene más bien, el carácter de una previa visualización del ser, en virtud de la cual el ente dado se articula provisionalmente en su ser" (Heidegger, 1927: 18).

Por lo cual, el contexto socio-histórico alrededor de una entidad, participa en la conformación de esta, pero no en su definición. "Esta visualización del ser que sirve de guía a la investigación brota de la comprensión mediana del ser en la que desde siempre nos movemos, y que en definitiva pertenece a la constitución esencial del Dasein mismo" (Heidegger, 1927: 18).

En trabajos como los de Hurtado de Mendoza y Gómez (1985), Troyo (1998) y Garnier y Troyo (2002) ligan el tamaño de las "plazas" con las dimensiones generales del complejo arquitectónico que le contiene; sin embargo, las extensiones de estos espacios no responden al volumen en sí del cuerpo que refiere al conjunto de estructuras.

Por lo tanto, en estas investigaciones se presupone que las características que poseen las "plazas" no están ligadas con las manifestaciones culturales que en ellas se practicaban, sino en relación a la proporcionalidad (con sus extensiones) del sitio arqueológico o las que en la actualidad se tienen registradas como tales.
Dicho razonamiento rechaza una posible preconcepción (por parte de sus constructores) de estos espacios, así como un conocimiento y manejo de la topografía, por lo que limita, en gran medida, el potencial de expresión sociourbano propio de las sociedades precolombinas; dejando la idea de un tipo de "evolucionismo constructivo" sin un orden o direccionamiento, donde las estructuras edificadas tenían que ser (de alguna manera) cohesionadas con otras para lograr una idea de complejo.

La concepción anterior muestra un carácter de convivio del espacio referido como plaza con los elementos que le conforman, "todo ambiente arquitectónico es una constelación muy compleja de tales sistemas espaciales, unos subordinados, otros coordinados, otros colindantes, y otros cruzando o rodeando a los demás" (Arnheim, 2001: 16). Entonces, el espacio debe ser concebido como una posibilidad para expresar una idea, "es como el receptáculo y la nodriza de todo lo que pasa ó deviene" (Platón, 1872:135); esto no implica que se limite a una coherencia dimensional o simétrica, sino que posee un significado por sí mismo.

Atinente a la funcionalidad, trabajos como los de Snarskis (1978), Ibarra (2003), Vázquez y Chapdelaine (2005), Hurtado de Mendoza y Troyo (2007-2008), García y Arce (2012) exponen las "plazas" como centros de intercambio; aseveración que goza de una amplia gama de connotaciones, por lo cual sería sinónimo de expresar su utilización como "un lugar de todo". Aunque los rangos temporales y espaciales en que esta manifestación arquitectónica se presentan, permitirían una variabilidad de usos, lo recomendable sería explorar sus funciones según cada caso y no asumir (acríticamente) la multiplicidad de usos per se; mucho menos sin un contexto claro en el registro arqueológico o sin haber sido científicamente excavados.

Para el entendimiento de un espacio es necesario su recreación y traducción a conceptos entendibles en nuestra realidad, por lo cual el (la) investigador(a) debe tomar una decisión, según el esquema investigativo elegido y la sustentación del mismo; con los cuales, conjugará la evidencia registrada de tal manera 
que podrá enfocar u hipotetizar una idea y no quedarse en generalidades; las cuales (aunque aportan información), deben de ser utilizadas para la construcción de una realidad social. "Esta incapacidad es culpable porque su causa no reside en la falta de inteligencia sino de decisión y valor para servirse por sí mismo de ella sin la tutela de otro" (Kant, 1964: 58).

El mismo caso se muestra y reitera en trabajos como los de Fonseca (1981) y García y Arce (2012), en donde asocian a las "plazas" a centros de "interacción social"; dicha acción se llevarían a cabo en cualquier espacio en que se halle evidencia arqueológica. Lo anterior, deja sin concretar los argumentos ni se apoya en datos claros que establezcan por qué se le asignan calificativos a estos espacios tales como "públicos" o "ceremoniales".

Otros textos (Hurtado de Mendoza y Troyo, 2007-2008 e Ibarra, 2003) refieren a las tumbas o áreas funerarias propias exclusivas de estos espacios ("plazas"), a pesar de este mismo tipo de evidencia es frecuente en los montículos y sectores externos a los sitios, así como en cementerios cercanos a los complejos arquitectónicos; por lo cual, este sería un argumento incorrecto.

Otro elemento que interfiere en el acercamiento respecto a las dinámicas o expresiones culturales llevadas a cabo en los espacios arqueológicos anotados, es la extrapolación de modelos sociales sin la discusión y reflexión de la información procedente del marco investigado. Lo anterior se refleja cuando se adjudican a las "plazas" actividades "religiosas" o "ceremoniales" sin una sustentación en la evidencia, si no por "tradición".

En cuanto a otros apelativos como "comercio", "ritual" o "reunión", asociados a las "plazas", estos refieren a todo un universo como a ninguno, es decir; ¿cuántas actividades de una persona diarias pueden ser catalogadas con los mismos calificativos? Se insiste en la razón de llevar a cabo aseveraciones arqueológicas con fundamento en la conjugación de la evidencia recolectada, con la orientación académica escogida y no predicciones fortuitas o juicios $a$ priori de los contextos estudiados.

Cabe destacar en este recuento nacional los trabajos de Snarskis (2003) Vázquez et al. (2009) así como Castillo y Peytrequín (2013); en los cuales, mediante argumentos específicos respecto a cierto conjunto de estructuras, hacen la referencia a una expresión humana que carga de significado determinada área; la misma fundamentada con evidencia (arquitectura, topografía y experiencia de campo).

Dichas investigaciones se diferencian de las antes mencionadas, en el hecho que los autores se posicionan en el contexto estudiado $\mathrm{y}$, con base en la evidencia recopilada, logran exponer una posible realidad de lo transcurrido en el sitio estudiado; dejando de lado otros calificativos y tradiciones, construyendo una idea del significado del paisaje en que se está. "La evidencia no es otra cosa que la 'la vivencia' de la verdad. Y la verdad no es vivida, naturalmente, en un sentido distinto de aquel en que puede ser en general vivencia el objeto ideal contenido en un acto real" (Husserl, 2006: 162).

En Snarskis (2003), Vázquez et al. (2009), como Castillo y Peytrequín (2013) no se remite a una respuesta generalizadora, espacial ni temporalmente, si no que se enfocan en la particularidad de la evidencia que recopilan los autores y se describe la experiencia de situarse en el espacio estudiado; "si la experiencia original fue de una relación directa cara a cara, seguirá siendo igual en la reproducción; si fue indirecta seguirá siendo indirecta. Pero ambas llevarán ahora el sello de la pretericidad" (Schütz, 1993: 235).

\subsection{El concepto de plaza reflejado en la evidencia arqueológica}

Debido a que distintas fuentes especialistas en el tema arquitectónico y urbanístico, no concluyen en una definición del término plaza, con la cual se pueda iniciar la deconstrucción, evidenciando lo dificultoso de tal tarea o lo ensañado de la tradición expuesta de dicho concepto que ni siquiera este es contemplado. 
Solo el título "Diccionario arquitectónico Ilustrado" de Orosco (2002) expresó una idea general de lo que el término "plaza" puede indicar, remitiendo la misma a:

Plaza: lugar ancho y espacioso, descubierto y rodeado de edificios, que se encuentra dentro o inmediato a una población, para su utilidad, adorno o desahogo (Orosco et al, 2002: 138).

En esta apreciación resaltan dos premisas, la primera hace referencia a que las plazas son construcciones sociales y no esquemáticas, es decir el espacio es constituido y conformado por la dinámica social que en determinado lugar se centraliza. El otro aspecto a resaltar es su carácter físico atinente a sus límites, ya que no se circunscribe por medio de estructuras propias, es decir, no puede ser definida por medio de muros específicos para dicho lugar, si no, mediante edificaciones con un sentido propio y no subordinado a la plaza.

La idea contenida en el concepto de plaza refiere a la edificación de un espacio por medio de la práctica continua, de un esquema de desarrollo urbano pero no planificado por el mismo. Por lo tanto, tomando esta premisa como base, dentro del ámbito de la arqueología el mismo puede ser identificado y definido como

\begin{abstract}
"plaza" se entendió como un espacio construido mediante la dinámica social cotidiana, este no posee un esquema específico; sino que lo constituye la apertura de un espacio por medio de dichas actividades dentro de un poblado o urbe (en este caso conjunto de estructuras). Por lo cual, no se encuentra delimitada por otras estructuras propias de ellas (muros), si no que a otras cuya funcionalidad es de cierta manera independiente de la "plaza” en sí (Castillo, 2014: 438).
\end{abstract}

Después de haber llevado a cabo este repaso por las distintas connotaciones teóricas e históricas que constituían el término plaza, su deconstrucción, así como su codificación en un término práctico y técnico, nos mostró la complejidad de significados que hay detrás de cada concepto utilizado en el trabajo y su el cuidado que se debe de tener en su empleo.

La importancia de llevar a cabo estos abordajes remite a dos aspectos, en primera instancia, ahora el investigador, como público en general esta consiente de lo que representa un plaza, desde aspectos materiales, físicos, políticos e históricos, construyendo personas más conscientes de nuestra realidad; por lo cual, podemos hacer inferencias más acorde a la evidencia material y arquitectónica de poblaciones antiguas, librando a las mismas, en parte, de los prejuicios conceptuales que posee nuestro entorno cultural.

\section{Conclusiones}

La definición de plaza refiere a un espacio inmerso dentro de diversas estructuras, las mismas poseen una funcionalidad específica acorde a la del conjunto de edificaciones; dentro de esté, su dinámica social establecería la conjunción de los espacios de tránsito en un área común, donde predominaría un intercambio no planificado, actividades varias y su no delimitación por parte de estructuras asignadas a este, si no por las otras expresiones materiales que componen el complejo arquitectónico.

Es por ello que este espacio aunque eje de la edificación de una planeación urbana, es configurado y establecido por la población mediante actividades diarias, de ahí características como su área, ubicación, la ausencia de límites en su establecimiento, además de la noción filológica que le se adjudica.

Desde un inicio la plaza ha sido referida como eje de la esquematización espacial urbana denominado plano damero, de la cual se tiene evidencia de su utilización desde el siglo $\mathrm{V}$ a.C. (Mossé, 1976) hasta la actualidad, la misma se ha fundamentado bajo preceptos de funcionalidad, orden y efectividad en cuanto al establecimiento de una población.

Dichas cualidades permitieron que dicho esquema fuera hasta cierto punto, medio de establecimiento de políticas coloniales, donde el mismo era adjudicado como centro del diseño de una población, así como el posicionamiento de otras edificaciones diferenciadas dentro 
de un conjunto de valores (religión, justicia, legislación, y comercio).

Este planteamiento urbanístico influyo la idea del establecimiento de un poblado, pensamiento que se ha reiterado en la lectura de dicho tópico referente a sociedades antiguas; limitando otras propuestas que puede explicar, denominar e interpretar lugares que son encasillados por dicha tradición; enmarcando el tópico de transformación de espacio dentro de un estructuralismo arquitectónico y urbanístico.

Esta postura no solo implicaría la introducción forzosa de esquemas cognitivos a sociedades ajenas en parámetros espaciales como temporales en marcos de pensamiento moderno occidental, sino una renuncia a otras posturas, perspectivas, relaciones del ser humano con su medio, como el significado y papel de la urbe en distintas sociedades, minimizando ámbitos multiculturales a planos trascendentales.

Como colorario, el termino plaza es un espacio público, sin limitantes materiales y parte de una ciudad, con el tiempo a este le fue otorgado el ser eje de esquemas urbanos, los cuales proponían una organización del terreno a marcos artificiales. Dicha disposición gozo de practicidad y trascendió en el tiempo hasta ser considerado como medio de adoctrinamiento social a poblaciones ajenas a la tradición occidental,; cuya utilización es reiterada dentro de parámetros prácticos como académicos.

Es por esta razón que se promueve la deconstrucción como reflexión de lo investigado, el análisis de sus constituyentes físicos, imaginarios, como históricos, con el fin de sustentar lo expresado con nuestros abordajes y ahondar en lo abarcado, no encasillándolo en esquemas tradicionales.

\section{Notas}

1. Se entiende paisaje como "la apropiación de un fenómeno comprendido en un espacio determinado, el cual posee relaciones con todo elemento que se halla en el mismo y sus transformaciones" (Castillo, 2016: 22).

\section{Bibliografía}

Arnheim, R. (2001). La forma visual de la arquitectura. Barcelona: Gustavo Gili.

Bollnow, O. F. (1963). Hombre y espacio. Barcelona: Labor.

Brugger, W. (2005). Diccionario de filosofía. Barcelona: Herder.

Castillo, M. y Peytrequin, J. (2013). "Paisaje y patrimonio. Reflexiones, diálogos y posibilidades". En: Aguilar, M. y Niglio O. La construcción del patrimonio cultural en Costa Rica. pp. 201-228. Roma: Aragne.

Castillo, M. (2014). Paisaje y arqueología: Arquitectura y conceptualización de las manifestaciones P-01, P-02, P-03 y "encierro" 1 en el sitio arqueológico Nuevo Corinto (L-72NC), Caribe Central, Costa Rica. (Tesis inédita de licenciatura). San José: Universidad de Costa Rica.

Castillo, M. (2016). “Contextualización histórica del concepto de paisaje, sus implicaciones filosóficas y científicas". Revista de filosofía de la Universidad de Costa Rica. Escuela de Filosofía. San José, Costa Rica. Volumen LV, 2016, número 143.

Chueca, G. (1981). Invariantes castizos de la arquitectura española. Barcelona: Dossat.

Corrales, F., Quintanilla, I. y Barrantes O. (1988). Historia precolombina y de los Siglos XVI y XVII del Sureste de Costa Rica. San José: Ministerio de Cultura, Juventud y Deportes.

Croché de Acuña,F. (1981). "Las plazas porticadas de la región Extremeña". En Arquitectura popular Extremeña. pp. 59-63. España: Badajoz. 
Diccionario de arquitectura y construcción. En: http://www.parro.com.ar/index.php. Consultado 19/12/2013, 14:00 h.

Fonseca, O. (1981). "Guayabo de Turrialba and its significance". En Benson, E. (ed.) Between continents/ between seas: precolumbian art of Costa Rica: 104-112. New York: Harry Abrams Inc.

García, S. y Arce, M. (2012). Sitio Nuevo Corinto (L-72-NC): Dinámicas socio productivas en los procesos de trabajo de la cerámica Mercedes Línea Blanca del componente La Selva (500-900 d.C.). Tesis para optar por el grado de Licenciatura en Antropología con énfasis en Arqueología. San José: Facultad de Ciencias Sociales, Escuela de Antropología. Universidad de Costa Rica.

Garnier, J. y Troyo, E. (2002). "El uso del espacio y la arquitectura del sitio". En Troyo E. Guayabo de Turrialba una aldea prehispánica compleja: 60-69. Capítulo 3. Centro de investigación y conservación del patrimonio cultural. San José: Ministerio de Cultura, Juventud y Deportes.

González, A. (1990). Plazas, iglesias y casas del concejo. Características e influencia en la configuración de las poblaciones. Cáceres: Norba-Arte, X.

Hartman, C. (1901). Archaeological Researches in Costa Rica. Stockholm: The Royal Ethnographical Museum.

Hardoy, J. y Aranovich, C. (1969). Urbanización en América Hispánica entre 1580 y 1630. $\mathrm{N}^{\circ}$ 11. BCIHE. Caracas: Universidad de Venezuela.

Heidegger, M. (1927). Ser y Tiempo. Trad. Jorge Eduardo Rivera. Escuela de Filosofía Universidad ARCIS. Edición electrónica tomada de www.philosophia. cl/ Consultado 15/08/2011, 13:00 h.
Hume, D. (2001). Tratado de la naturaleza humana. Libros en la red, tomado de www. dipualba.es/publicaciones Consutlado 19/12/2013, 19:00 h.

Humboldt, A. (1956). Viaje a las regiones equinocciales del Nuevo Continente hecho en 1799, 1800, 1801, 1802, 1803 y 1804. Trad. L. Alvarado y J. Nucete Sardí.I-V. Caracas: Ministerio de Educación Nacional.

Hurtado de Mendoza, L. y Gómez J. (1985). “Breve descripción comparativa de dos regiones arqueológicas en Costa Rica: Guayabo de Turrialba y Tálari de Pacuare". San José: Vínculos 11 (1-2). pp. 67-99.

Hurtado de Mendoza, L. y Troyo, E. (20072008). "Simbología de poder en Guayabo de Turrialba". San José: Cuadernos de Antropología. No. 17-18. pp. 23-65.

Husserl, E. (2006). Investigaciones lógicas I. Madrid: Alianza.

Ibarra, E. (2003). Las sociedades cacicales en el Siglo XVI. San José: Universidad de Costa Rica.

Kant, I. (1964). "Respuesta a la pregunta ¿Qué es la Ilustración?". En Filosofía de la historia. Buenos Aires: Nova.

Menéndez, J. L. (1997). Las fuentes antiguas sobre el urbanismo de Hipodamo de Mileto. Barcelona: D`Art, 23.

Morse, R. (1942). "The urban development of colonial Spanish América". En The Cambridge History of Latin América. Vol. II. New York: Bulletin 24.

Mossé, C. (1976). Los orígenes del socialismo en la Antigüedad. En Jacques Droz (dir.). Historia general del socialismo. De los 
orígenes a 1875 (pp. 89-90) Barcelona: Destino.

Mumford, L. (1979). La ciudad en la historia: Sus orígenes. Buenos Aires: Infinito.

Norberg-Schulz, C. (1967). Intention und Methode in Architektur. Alemania: Der Architekt. pp. 218-225.

Orosco, G. (2002). Diccionario arquitectónico ilustrado. Bolivia: Centro de Conservación del Patrimonio Artístico y Arquitectónico.

Padrón, R. (2002). "Mapping Plus Ultra: Cartography, Space, and Hispanic Modernity", Representations. Vol. 79, pp. 28-60. California: University of California Press.

Parsons, T. (1966). Societies. Nueva Jersey: Prentice Hall.

Platón. (1872). Timeo. Madrid: Patricio de Azcárate.

Schütz, A. (1993). La construcción significativa del mundo social. Introducción a la sociología comprensiva. Barcelona: Paidós.

Snarskis, M. (1978). The archaeology of the Central Atlantic Watershed of Costa Rica. Disertación doctoral (Ph.D.). New York: Department of Anthropology, Columbia University.
Snarskis, M. (2003). "From Jade to Gold in Costa Rica: How, Why, and When". En Quilter, J. and Hoopes, J. Gold and Power in Ancient Costa Rica, Panama, and Colombia. Washington, D.C.: Dumbarton Oaks Research Library and Collection.

Stone, D. (1976). Arqueología de la América Central. Guatemala: Piedra Santa.

Troyo, E. (1998). "La Arquitectura en la Costa Rica Antigua". En Fonseca, E. y E. Garnier. Historia de la Arquitectura en Costa Rica: 15-79. Capítulo 1. San José: Fundación de Museos del Banco Central.

Vázquez, R. (2005). Desarrollo y alcances del poder cacical amerindio en el Sur de Centro América, el sitio Las Mercedes Caribe Central de Costa Rica. Propuesta de investigación presentada a la Comisión Arqueológica Nacional. Manuscrito. San José: Departamento de Antropología e Historia, Museo Nacional de Costa Rica.

Vázquez, R., Rosenswing, R., Latimer, J., Alarcón, G. \& Sohet, B. (2009). Informe Arqueológico 021-09, Desarrollo y alcances del poder cacical amerindio en el sur de Centroamérica: sitios Las Mercedes-1 y La Iberia, Caribe Central de Costa Rica/Temporada 2009. Manuscrito. San José: Departamento de Antropología e Historia, Museo Nacional de Costa Rica.

Wittgenstein, L. (1999) Investigaciones filosóficas. Barcelona: Crítica.

\section{(c) $\Theta \Theta \Theta$}

Este obra está bajo una licencia de Creative Commons Reconocimiento-NoComercial-SinObraDerivada 4.0 Internacional. 
